Unusual presentation of more common disease/injury

\title{
Concomitant axillary mycobacteriosis and neuro-sarcoidosis: diagnostic pitfalls
}

\author{
Roderich Meckenstock, ${ }^{1}$ Audrey Therby, ${ }^{1}$ Catherine Chapelon-Abric, ${ }^{2}$ Chantal Nifle, ${ }^{3}$ \\ Jean Paul Beressi, ${ }^{4}$ Constance Lebas, ${ }^{5}$ Alix Greder-Belan ${ }^{1}$
}

1Department of Internal Medicine and Infectious Diseases, Versailles Hospital, Le Chesnay, France;

2Department of Internal Medicine, Pitié Salpétrière University Hospital, Paris, France;

${ }^{3}$ Department of Neurology, Versailles Hospital, Le Chesnay, France;

${ }^{4}$ Department of Diabetology and Endocrinology, Versailles Hospital, Le Chesnay, France;

5Department of Gerontology, Versailles Hospital, Le Chesnay, France

Correspondence to Dr Roderich Meckenstock, rmeckenstock@ch-versailles.fr

\section{Summary}

There are many similarities between mycobacteriosis, in particular, tuberculosis, and sarcoidosis such as predominant intrathoracic localisation (even if all organs and tissues may be concerned), great variability of phenotypic expression, and granulomatous inflammatory reaction, caseous necrosis not being an absolute criterion of tuberculosis. Moreover, microbial (or mycobacterial?) agents may play a role in the pathogenesis of sarcoidosis which remains a diagnosis of exclusion particularly in atypical cases.

The authors report a case of a non-immunocompromised female patient who presented, simultaneously, isolated axillary tubercular adenitis and neuro-sarcoidosis without any other localisation. This case illustrates the difficulty to distinguish between both of these two diseases and thus to choose an adequate treatment when diagnosis is not proven. Moreover, our patient (human leucocyte antigen B27 positive) presented symptoms of spondylarthritis which also may have a nosological link with tuberculosis or sarcoidosis.

\section{BACKGROUND}

There are many similarities between mycobacterial infections, in particular tuberculosis, and sarcoidosis, such as predominant intrathoracic localisation (about $90 \%$ ), even given that all organs and tissues may be concerned, great variability of phenotypic expression, and granulomatous inflammatory reaction, caseous necrosis not being an absolute criterion of tuberculosis. Moreover, microbial (or mycobacterial?) agents may play a role in the pathogenesis of sarcoidosis, which remains a diagnosis of exclusion, particularly in atypical cases.

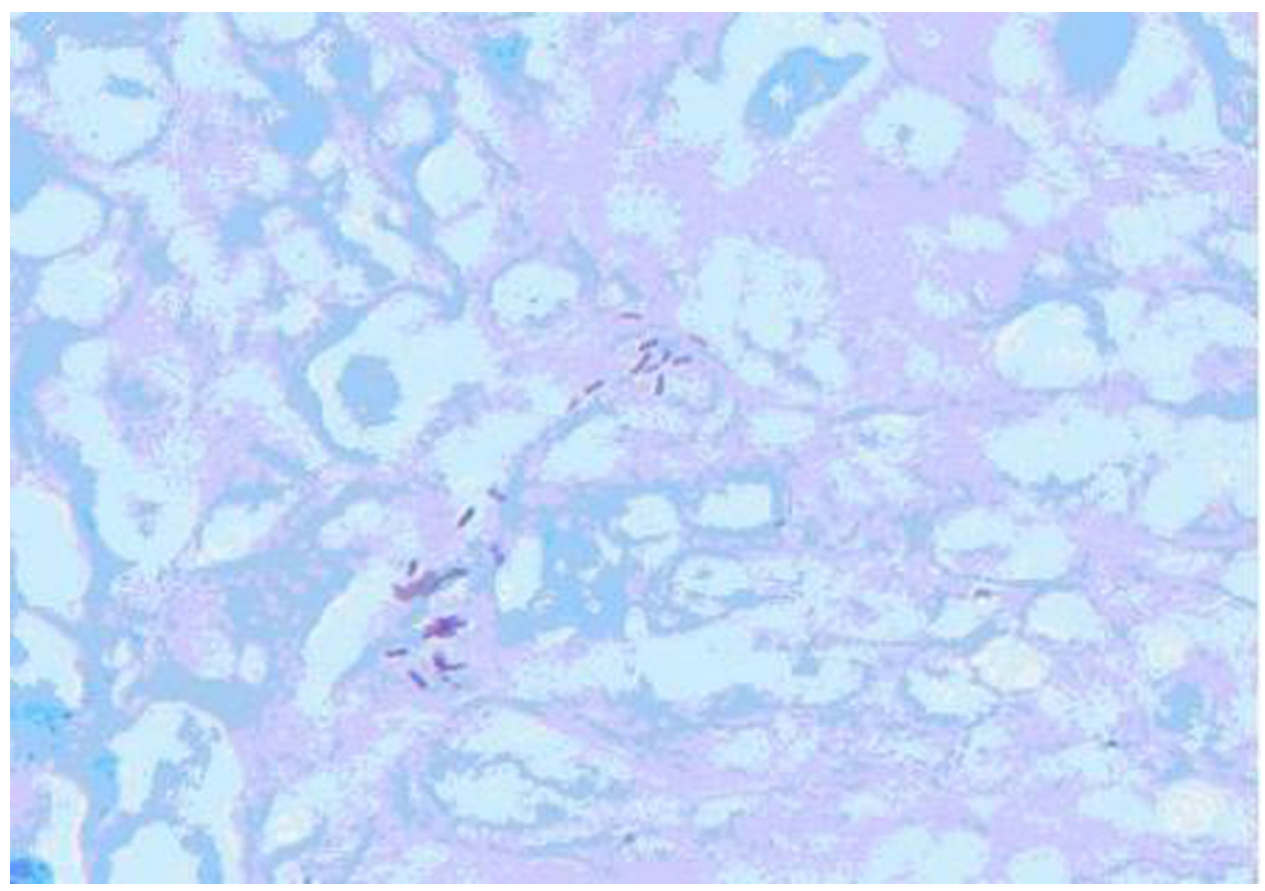

Figure 1 Ziehl stain (axillary adenopathy). 


\section{BMJ Case Reports}

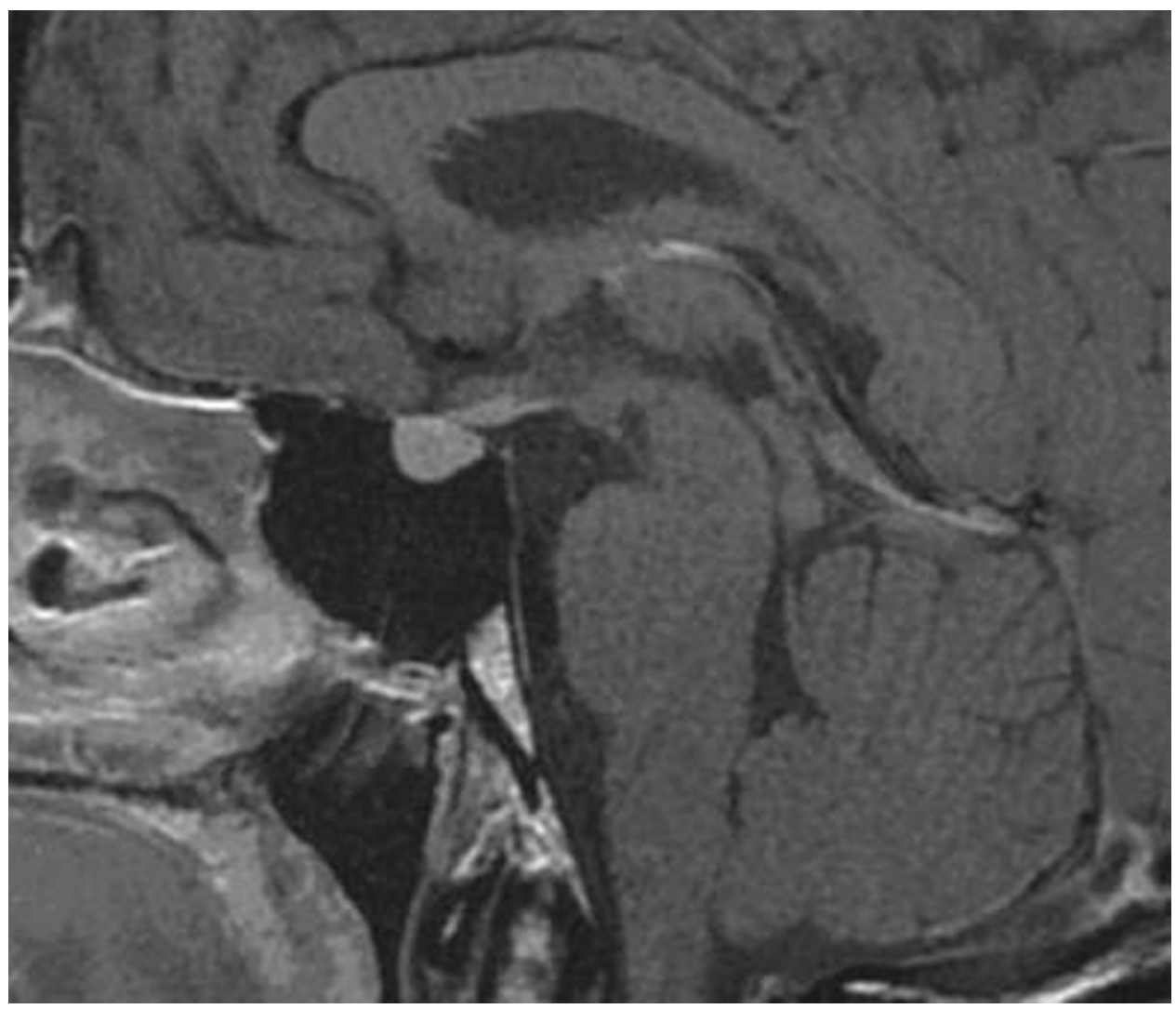

Figure 2 Homogeneous contrast of the pituitary gland (T1 gadolinium sagittal).

We report a case of a non-immunecompromised female patient who presented, simultaneously, isolated axillary mycobacterial (tuberculous?) adenitis and neuro-sarcoidosis without any other localisation. This case illustrates the difficulty in distinguishing between these two diseases and thus in choosing an adequate treatment in the absence of diagnostic proofs. Moreover, our patient (human leucocyte antigen (HLA) B27 positive) presented symptoms of spondylarthritis which may have a nosological link with sarcoidosis.

\section{CASE PRESENTATION}

A 50-year-old caucasian woman consulted for nodular erythema, arthralgia of ankle and isolated axillary adenopathies which already had occurred 3 months before, persisting after antibiotic treatment which had been administered after withdrawal of a foreign body on a homolateral finger tip. Three weeks before the first occurrence of adenopathies, she had travelled to Cairo for 4 days; there was not any known contact with tuberculosis. Moreover, she was suffering from diarrhoea and inflammatory spine and heel pain. Her medical history included benign breast tumour, hysterectomy and smoking; two members of her family had HLA B27 positive spondylarthritis. Physical examination was normal besides left axillary adenopathy of $20 \mathrm{~mm}$.

\section{INVESTIGATIONS}

Biological screening revealed a mild inflammatory syndrome and a slight elevation of ACE; none of the serologies was in favour of acute bacterial or viral infection, in particular, serologies of HIV and bartonella were negatives, serologies of Epstein-Barr virus, cytomegalovirus and toxoplasmosis revealed acquired immunity, and there was no evidence of fungal infection. Autoimmune diseases could be ruled out biologically. HLA B27 was positive, intradermal tuberculin test at $10 \mathrm{~mm}$. Spine $\mathrm{x}$ - ray and colonoscopy were normal as well as CT body scan, besides two left axillary lymph nodes. Lymph node cytodiagnosis showed adenitis but all microbial cultures were negative, whereas on microbiopsy, granulomatous, gigantocellular and necrotising adenitis was found but neither caseous necrosis nor positive Ziehl coloration was present. Cultures of mycobacteria remained negative. Surprisingly, a second analysis of the axillary lymph node, performed several months later, revealed the presence of acid-alcohol resistant bacilli (AARB) by a positive Ziehl stain (figure 1).

\section{TREATMENT}

Inspite of the lack of proof for tuberculosis upon initial investigations, patient received a classical antituberculous treatment for a period of 6 months. In the following weeks, increasing back pain incited to start a treatment of spondylarthritis by a disease modifying antirheumatic drug (sulfasalazidine). This treatment was of no benefit but gave rise to a DRESS syndrome (drug reaction with eosinophilia and systemic symptoms) which developed favourably under high dose dermocorticoids.

\section{OUTCOME AND FOLLOW-UP}

Later on, patient presented asthenia, hormonal analysis revealing suprarenal insufficiency of central origin. But 


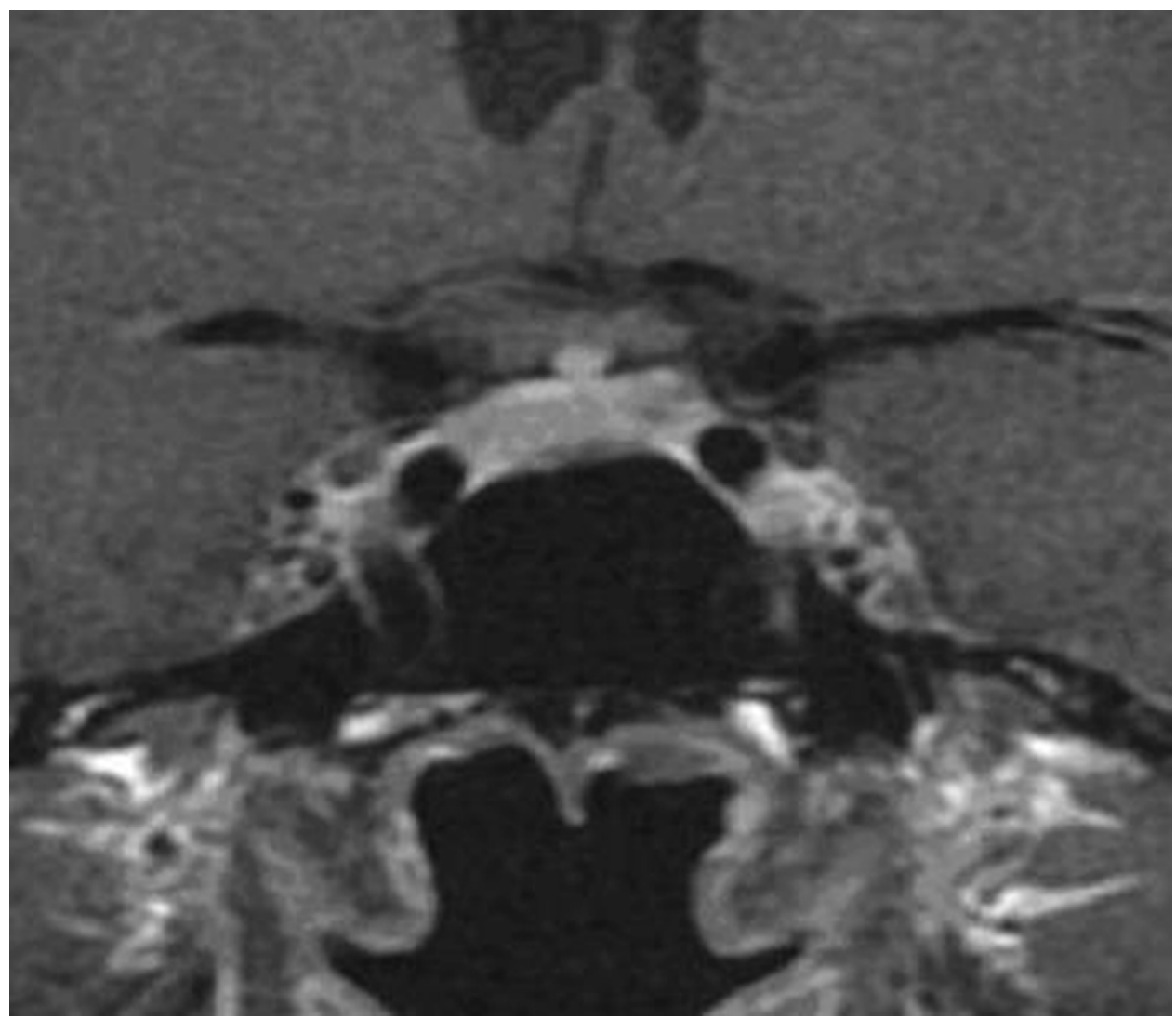

Figure 3 Homogeneous contrast of the pituitary gland (T1 gadolinium coronal).

asthenia persisted in spite of hydrocortisone replacement therapy, and slight transitory facial paralysis occurred. At this time, MRI of the brain revealed signs of inflammation in the stalk of pituitary gland and at the bottom of the third ventricle (figures 2 and 3), and ACE level in cerebrospinal fluid (CSF) was at twice the normal upper value. Hence neurosarcoidosis was diagnosed, even if complete screening for other localisations of sarcoidosis (CT body scan, cardiac MRI, salivary gland biopsy) remained negative. High dose oral corticotherapy (prednisone) was begun at $1 \mathrm{mg} / \mathrm{kg} / \mathrm{day}$, associated with methotrexate at $20 \mathrm{mg} /$ week intramuscular 3 months later. Patient felt much better and was able to take up a half time job again. Prednisone doses could be lowered by $2,5 \mathrm{mg}$ steps every 2 weeks but relapse of asthenia occurred at a $7 \mathrm{mg}$ daily dose of prednisone, inciting to re-increase doses slightly. Nevertheless, at 18 months, immunosuppressive treatment had to be considered as insufficient, clinical signs persisting at prednisone doses at more than $10 \mathrm{mg} /$ day. Moreover, she presented intense inflammatory spine pain at prednisone doses beneath $12 \mathrm{mg} /$ day, in the context of spondylarthritis. Hence, methotrexate was replaced by mycophénolate mofétil $2 \mathrm{~g} /$ day and hydroxychloroquine $400 \mathrm{mg} /$ day (the latter being rapidly stopped because of ophthalmologic side effects).

Actually, at 20 months of treatment for neurosarcoidosis, asthenia is very fluctuating and may be partially linked to dysthymic disorders (depression) and hormonal imbalance (menopause). Moreover, sleep apnoea syndrome has been discovered recently but treated adequately.

\section{DISCUSSION}

In spite of the absence of AARB on initial analysis of biopsy of the adenopathy, and mycobacterial culture remaining negative, we betted on tuberculous adenitis and treated upon this hypothesis. Indeed, the probability of adenitis by mycobacterium avium complex is very low in immunocompetent and adult patients, ${ }^{1}$ and in principle, our patient had no risk of developing mycobacterium marinum infection. By the way, OMS recommendations allow the diagnosis of tuberculosis in the sole presence of AARB. In tuberculosis, extrapulmonary localisations are found in 10 to $25 \%$ of all cases, ${ }^{2-4}$ more than half of them being situated in the lymph nodes. ${ }^{4}$ In a series of 636 cases, only 10 presented isolated axillary tuberculous adenopathy. ${ }^{4}$ Differential diagnosis of axillary adenopathy includes sarcoidosis, lymphoma, breast cancer and infectious diseases such as bartonella. Concomitant breast cancer and axillary tuberculosis have been described. 67

Like tuberculosis, sarcoidosis is intrathoracic in up to 90\% of all cases. ${ }^{3}{ }^{8-10}$ Extrathoracic localisations occur in about $20 \%{ }^{11}$ and up to $50 \%$ in older patients, ${ }^{12}$ their incidence being yet higher in series of autopsies. ${ }^{13} 14$ All tissues and organs may be affected. A majority of these patients have simultaneous thoracic sarcoidosis or typical clinical manifestations of sarcoidosis but isolated extrathoracic forms may be very difficult to identify as sarcoidosis. Even biopsy, to be performed whenever possible, may not always allow establishment of diagnosis. The American Thoracic Society/European Respiratory Society/World Association of Sarcoidosis and other Granulomatous consensus ${ }^{8}$ requires convergence of a compatible clinical, radiological and 
biological presentation, the presence of typical granuloma and the absence of other types of granulomatosis. Thus, sarcoidosis is to be a diagnosis of exclusion. Some malignant lesions or tuberculosis can mimic lesions of sarcoidosis and can occur simultaneously or successively. ${ }^{15} 16$ Moreover, implication of mycobacteries or propionibacteries has been discussed in the pathogenesis of sarcoidosis, ${ }^{17-19}$ with a functional deficiency of toll like receptor (TLR-9). ${ }^{20}$

Incidence of neuro-sarcoidosis is estimated between 5 and $25 \%^{11} 21-23$ but only $10 \%$ of these patients have no other localisation. ${ }^{14}$ It is twice as high in series of autopsies, ${ }^{13}$ remaining without clinical manifestations in many cases. It is presented as meningitis, invasion of the hypothalamus, the pituitary gland or cranial nerves, or as tumour lesions. ${ }^{13} 1422-24$ Clinical expression is very polymorphous, with numerous non-specific symptoms ${ }^{25}$ such as isolated psychiatric symptoms comprising dementia or asthenia. ${ }^{23-24} 26$ Magnetic resonance neurography is contributive less by specificity than by localisation of neurosarcoidosis lesions. ${ }^{14} 2123$ ACE in CSF is elevated in only 33 to $58 \%$ of cases. ${ }^{11} 14$ Differential diagnosis includes lymphoma, vasculitis, Whipple's disease, Lyme borreliosis and tuberculosis. ${ }^{11} 142326$ Biopsy can be realised in only $20 \%$ of neuro-sarcoidosis, ${ }^{21}$ so that diagnosis may be particularly difficult in his isolated form. Based on the criteria of pertinence defined by Zajicek et al. ${ }^{11}$ our patient had probable neuro-sarcoidosis; nevertheless, it was difficult to establish diagnosis in the absence of other localisations and in the presence of concomitant tuberculosis.

Follow-up and evaluation of treatment of neurosarcoidosis is particularly difficult when clinical manifestations are non-specific like asthenia or dysthymic disorders which may either be neuro-psychiatric symptoms of sarcoidosis, or reactionnal. Moreover, in our patient, active spondylarthritis with inflammatory signs may contribute to asthenia as well and interfere with global clinical evaluation, and even with the choice of treatment modalities.

Several cases of spondylarthritis associated with sarcoidosis have been published ${ }^{27-31} ; 14$ of them were summarised in $2002^{27}$. Spondylarthritis could be a rheumatologic phenotype of sarcoidosis, but presence of HLA B27 (our case, Connault et al. $)^{31}$ is rather in favour of coincidence of two nosological entities.

\section{Learning points}

- Extrathoracic phenotypes of mycobacterial infections (in particular: tuberculosis) and sarcoidosis are not so rare and often very similar even if isolated axillary mycobacteriosis (tuberculosis) and isolated neurosarcoidosis are exceptional; they may constitute serious diagnostic problems in case of single localisations.

- In particular, isolated neuro-sarcoidosis needs to rule out any other differential diagnosis, therapeutic consequences being important.

- Moreover, tuberculosis and sarcoidosis may occur successively or simultaneously; in passing, etiopathological links are discussed.

- Spondylarthritis may belong to extrathoracic sarcoidosis phenotypes.
Acknowledgements Acknowledgements to Mr Kurt Lueders for revision of traduction.

\section{Competing interests None.}

Patient consent Obtained.

\section{REFERENCES}

1. Field SK, Fisher D, Cowie RL. Mycobacterium avium complex pulmonary disease in patients without HIV infection. Chest 2004;126:566-81.

2. Giovinale M, Fonnesu C, Soriano A, et al. Atypical sarcoidosis: case reports and review of the literature. Eur Rev Med Pharmacol Sci 2009;13 Suppl 1:37-44.

3. Ilgazli A, Boyaci H, Basyigit l, et al. Extrapulmonary tuberculosis: clinical and epidemiologic spectrum of 636 cases. Arch Med Res 2004;35:435-41.

4. Mezghani S, Hamdi S, Laadhar A, et al. La tuberculose extrapulmonaire. Rev Mal Respir 2003;20:153-66.

5. Hochedez $\mathbf{P}$, Zeller $\mathrm{V}$, Truffot $\mathrm{C}$, et al. [Lymph-node tuberculosis in patients infected or not with HIV: general characteristics, clinical presentation, microbiological diagnosis and treatment]. Pathol Biol 2003;51:496-502.

6. Tulasi NR, Raju PC, Damodaran V, et al. A spectrum of coexistent tuberculosis and carcinoma in the breast and axillary lymph nodes: report of five cases. Breast 2006;15:437-9.

7. Jerbi M, Hidar S, El Moueddeb S, et al. [Tuberculous axillary lymphadenitis: an unusual presentation]. Rev Med Liege 2007;62:188-9.

8. ATS/ERS/WASOG Committee. Statement on sarcoidosis. Am J Respir Crit Care Med 1999;160:736-55.

9. Baughman RP, Lower EE, du Bois RM. Sarcoidosis. Lancet 2003;361:1111-8.

10. Bouvry D, Uzunhan Y, Naccache JM, et al. [Atypical sarcoidosis]. Rev Med Interne 2008;29:46-53.

11. Zajicek JP, Scolding NJ, Foster 0 , et al. Central nervous system sarcoidosisdiagnosis and management. OJM 1999;92:103-17.

12. Rockoff SD, Rohatgi PK. Unusual manifestations of thoracic sarcoidosis. AJR Am J Roentgenol 1985:144:513-28.

13. Iwai K, Tachibana T, Takemura T, et al. Pathological studies on sarcoidosis autopsy. I. Epidemiological features of 320 cases in Japan. Acta Pathol Jpn 1993;43:372-6.

14. Dubas F, Nicolas G. Neurosarcoïdose. http://www.em-consulte.com/ article/2508 (accessed 18 June 2001)

15. Oluboyo PO, Awotedu AA, Banach L. Concomitant sarcoidosis in a patient with tuberculosis: first report of association in Africa. Cent Afr J Med 2005;51:123-5.

16. Wong CF, Yew WW, Wong PC, et al. A case of concomitant tuberculosis and sarcoidosis with mycobacterial DNA present in the sarcoid lesion. Chest 1998:114:626-9.

17. Hörster R, Kirsten D, Gaede Kl, et al. Antimycobacterial immune responses in patients with pulmonary sarcoidosis. Clin Respir J 2009;3:229-38.

18. Oswald-Richter KA, Beachboard DC, Zhan X, et al. Multiple mycobacterial antigens are targets of the adaptive immune response in pulmonary sarcoidosis. Respir Res 2010;11:161.

19. Oswald-Richter KA, Drake WP. The etiologic role of infectious antigens in sarcoidosis pathogenesis. Semin Respir Crit Care Med 2010;31:375-9.

20. Veltkamp M, Van Moorsel CH, Rijkers GT, et al. Toll-like receptor (TLR)-9 genetics and function in sarcoidosis. Clin Exp Immunol 2010;162:68-74.

21. lizuka T, Sakai F. [Neurosarcoidosis]. Nippon Rinsho 2002;60:1785-93.

22. Pawate S, Moses H, Sriram S. Presentations and outcomes of neurosarcoidosis: a study of 54 cases. OJM 2009;102:449-60

23. Chapelon-Abric C, Zizza JM, Piette JC, et al. Neurosarcoidosis: signs, cours and treatment in 35 confirmed cases. Medicine 1990:69:261-76.

24. Neurosarcoïdose. Cours de neurologie. http://www.medix.free.fr/cours/ neurosarcoidose.php (accessed 18 June 2001).

25. Joseph FG, Scolding NJ. Neurosarcoidosis: a study of 30 new cases. J Neurol Neurosurg Psychiatr 2009;80:297-304.

26. Chauveheid MP, Sbai A. Hydrocéphlie brutale chez un homme de 36 ans. Médecine thérapeutique 2001;7:88-91.

27. Abouzahir A, El Maghraoui A, Tabache F, et al. [Sarcoidosis and ankylosing spondylitis. A case report and review of the literature]. Ann Med Interne (Paris) 2002;153:407-10.

28. Sezer I, Melikoglu MA, Cay HF, et al. A co-occurrence of sarcoidosis and ankylosing spondylitis: a case report. Rheumatol Int 2008;28:605-7.

29. Stucki G, von Felten A, Speich R, et al. Ankylosing spondylitis and sarcoidosis-coincidence or association? Case report and review of the literature. Clin Rheumatol 1992;11:436-9.

30. Levy S, Sandhu V. Ankylosing spondylitis and pulmonary sarcoidosis-a case report and discussion of the literature. Rheumatology (Oxford) 2008;47:1733-4.

31. Connault C, Durant C, Lebreton O, et al. Spondylarthropathie HLA B27 positive, sarcoïdose et uvéite: un continuum nosologique ou un diagnostic différentiel complexe? Rév Med Int 2009:30:S 118. 


\section{BMJ Case Reports}

This pdf has been created automatically from the final edited text and images.

Copyright 2011 BMJ Publishing Group. All rights reserved. For permission to reuse any of this content visit http://group.bmj.com/group/rights-licensing/permissions.

BMJ Case Report Fellows may re-use this article for personal use and teaching without any further permission.

Please cite this article as follows (you will need to access the article online to obtain the date of publication).

Meckenstock R, Therby A, Chapelon-Abric C, Nifle C, Beressi JP, Lebas C, Greder-Belan A. Concomitant axillary mycobacteriosis and neuro-sarcoidosis: diagnostic pitfalls. BMJ Case Reports 2011;10.1136/bcr.03.2011.4043, date of publication

Become a Fellow of BMJ Case Reports today and you can:

- Submit as many cases as you like

- Enjoy fast sympathetic peer review and rapid publication of accepted articles

- Access all the published articles

Re-use any of the published material for personal use and teaching without further permission

For information on Institutional Fellowships contact consortiasales@bmjgroup.com

Visit casereports.bmj.com for more articles like this and to become a Fellow 